\title{
Multisystemic therapy: an effective violence prevention approach for serious juvenile offenders
}

\author{
Scott W. Henggeler*, Phillippe B. Cunningham, Susan G. Pickrel, \\ Sonja K. Schoenwald and Michael J. Brondino
}

\begin{abstract}
This article provides an overview of a treatment approach, Multisystemic Therapy (MST), that has demonstrated long-term reductions in criminal activity and violence among youth at high-risk for perpetrating violence. Importantly, central aspects of MST are consistent with the recent public health agenda of violence prevention in the U nited States. Moreover, as demonstrated from the findings of controlled clinical trials evaluating MST with serious juvenile offenders, the viability of the public health approach is supported.
\end{abstract}

(C) 1996 The A ssociation for Professionals in Services for A dolescents

\section{Introduction}

The rising tide of crime and violence in A merica has caught our youth in its everexpanding wake. A merican youth are intimately acquainted with violence as both perpetrators and victims. Crime statistics show that adolescents are responsible for approximately $29 \%$ of all crime and $17 \%$ of violent crime (FBI, 1992). Commensurate with their rates of offending, adolescents also have high rates of victimization. For example, homicide has emerged as the second leading cause of death among adolescents, and those aged 15-34 are at highest risk of non-fatal assault (cited in M ercy et al., 1993).

The public, outraged by the escalation of youth violence and concerned about the health and vitality of the young, has mandated that "something be done". This mandate has been met with costly and largely ineffective "feel good" criminal justice initiatives such as deterrence and fear-based programs (e.g. shock incarceration programs, bootcamps), which research suggests may have iatrogenic effects (Lipsey, 1992; H enggeler and Schoenwald, 1994). W hile such responses are politically expedient, and better than nothing according to some policy-makers, the violence epidemic continues largely unabated.

Recently, a great deal of enthusiasm has been generated by placing violence under the auspices of public health with its attendant emphasis on primary prevention.

Reprint requests and correspondence concerning this article should be addressed to $\mathrm{S}$. W. Henggeler, Department of Psychiatry \& Behavioral Sciences, Family Services Research C enter, M edical U niversity of South Carolina, 171 A shley A venue, Charleston, SC 29425-0742, U.S.A.

*Preparation of this article was supported by the $\mathrm{N}$ ational Institute on Drug A buse, Grant DA-08029, and N ational Institute of M ental $\mathrm{H}$ ealth, G rant M H 51852-01A 1. 
A cknowledging violence as a public health issue is refreshing and offers new hope, as M ercy et al. noted:

A new vision for how A mericans can work together to prevent the epidemic of violence now raging in our society has emerged from the public health community. This new vision places emphasis on preventing violence before it occurs, making science integral to identifying effective policies and programs, and integrating the efforts of diverse scientific disciplines, organizations, and communities. A sustained effort at all levels of society will be required to successfully address this complex and deeply rooted problem (1993, pp. 8).

This article provides an overview of a treatment approach, M ultisystemic Therapy (M ST ; Henggeler and Borduin, 1990), that has demonstrated long-term reductions in criminal activity and violence among those youth at greatest risk for perpetrating violence. Importantly, central aspects of MST are consistent with the recent public health agenda concerning violence prevention. M oreover, as demonstrated from the findings of controlled clinical trials (Henggeler et al., 1992, 1993; Borduin et al., 1995), the success of MST supports the viability of the public health approach when applied to serious juvenile offenders.

\section{Public health and violence prevention}

A Ithough the advance of public health into violence prevention is in its infancy, public health approaches have previously made significant contributions in other health-related areas including preventable diseases, smoking, and unintentional injuries. For example, mortality rates from contagious and infectious diseases, motor vehicle injuries, and chronic diseases associated with lifestyles (e.g. smoking and heart disease) have decreased due to public health's investment in and commitment to prevention (Mercy et al., 1993). Proponents envisage that a similar investment and commitment to violence prevention by the public health community will result in dramatic and substantial reductions in rates of premature death, disability, and intentional injury caused by violence.

Public health approaches assume that violence can be prevented and place a special emphasis on primary prevention (M ercy et al., 1993). Primary prevention programs aim to prevent violence from occurring (i.e. reducing the incidence of new cases), as opposed to reducing the severity or duration of disorder (i.e. secondary prevention), or rehabilitating/ treating (i.e. tertiary prevention) perpetrators of violence or victims of violence. A s such, primary prevention is conceptualized as proactive as opposed to reactive (Leitenberg, 1987).

$\mathrm{H}$ istorically, three strategies within public health have been useful in primary prevention (A lbee, 1989). The first strategy involves identification of risk-factors (e.g. pathogens, noxious agents), with subsequent interventions designed to neutralize or eliminate such agents. The second strategy focuses on protective factors (i.e. individual and environmental characteristics that ameliorate or buffer a person's response to risk factors) to strengthen host characteristics that increase resistance (inoculate) to the pathogen. In the third strategy, interventions are designed that prevent or block the transmission of the pathogen to the host. Thus, primary prevention entails counteracting risk factors and reinforcing protective factors in an effort to neutralize processes that contribute to human pathology (Coie et al., 1993).

MST may best be conceptualized as tertiary or secondary prevention in its immediate application. Nevertheless, MST shares characteristics of primary prevention approaches. 
These include reinforcing protective factors and ameliorating or addressing systematically those factors associated with dysfunction generally, and antisocial behavior in particular.

\section{MST and the neutralization of risk factors}

A key assumption of MST is that treatment effectiveness rests upon a thorough understanding of the etiological factors associated with antisocial behavior. These factors have been explicated in multidimensional causal modeling studies (e.g. A gnew, 1985; Elliott et al., 1985; Patterson and Dishion, 1985; Simcha-Fagan and Schwartz, 1986; Fagan and W exler, 1987; Huizinga et al., 1993; Office of Juvenile Justice and Delinquency Prevention, 1993) which demonstrate that antisocial behaviour is multidetermined, with important correlates pertaining to the individual (e.g. low cognitive functioning, poor social skills), family (e.g. low warmth, in effective discipline, parental criminal behaviour), peers (e.g. association with deviant peers), school functioning (e.g. poor academic performance, dropping out), and community (e.g. a criminal subculture) (for comprehensive reviews see Kazdin, 1987; H enggeler, 1991). For example, Elliott et al. (1985), in a longitudinal evaluation of a representative national sample of adolescents, found that delinquency was predicted directly by prior delinquency and association with deviant peers, and that association with deviant peers was predicted indirectly by family and school difficulties. This study as well as others attest to the multidetermined etiology of serious antisocial behavior.

Given the multidetermined etiology of antisocial behaviour in adolescents, MST interventions are individually tailored to ameliorate those factors within and across the various systems or subsystems (i.e. family, peers, school, community) contributing to antisocial behavior. Consequently, any and all factors determined to attenuate treatment outcome are targeted. For example, barriers to effective parenting, such as high stress, low social support, parental substance abuse, marital problems, or lack of knowledge are often the initial targets of M ST interventions.

\section{MST and the promotion of protective factors}

In addition to ameliorating risk-factors, MST also empowers parents and youth to deal effectively and independently with future difficulties. A s noted by Rappaport (1981), the aim of empowerment is to enhance the possibilities of individuals to control their own lives. A $n$ empowerment perspective also suggests that when new competencies are needed they are best learned in the context of one's social ecology (Rappaport, 1981).

Commensurate with an empowerment ideology, MST treatment goals are developed in full collaboration with youth and parents, and MST interventions emphasize family strengths and are implemented in the family's environment. For example, a great deal of therapist time is initially devoted to establishing a positive therapeutic alliance with parents/ guardians. Once established, interventions are designed to provide the youth and parents with the resources and/or skills needed to successfully navigate their social ecology. A focus on building competencies (e.g. problem-solving skills), resources (e.g. social support), and concrete services (e.g. adequate housing) lays the foundation for stable family functioning across life transitions and attendant stressors. Such a foundation can provide 
positive and long-term impact on children's psychosocial development (Winett et al., 1989).

\section{MST and blocking}

A Ithough, the "social disease" entities responsible for violence are multiple and less clear than those related to specific biological diseases, certain "social circumstances" appear to be fertile breeding conditions for violence. As mentioned above, one of the strongest predictors of violent behavior (and delinquency) is association with deviant peers. Several factors that directly influence association with deviant peers are low parental monitoring and low school integration. Consequently, MST treatment goals often include provisions for increasing parental monitoring, severing relationships with deviant peers, developing relations with prosocial peers, and increasing educational/vocational options.

In summary, MST has much in common with the public health agenda of violence prevention, including neutralizing risk factors, promoting protective factors, and blocking the transmission of noxious agent(s). M ST follows a social-ecological theory of behavior and recognizes that optimal child development is the result of a complex set of interdependent factors that traverse multiple levels of influence. Consequently, providing prevention strategies that are flexible, comprehensive and multifaceted may not only result in reduced antisocial behavior for the target child, but for other children in the family as well.

\section{Two recent controlled clinical trials of MST}

To date, MST has enjoyed considerable success with clinical populations that have historically been recalcitrant to treatment. The effectiveness of M ST has been supported in clinical trials with impoverished inner-city juvenile offenders ( $H$ enggeler et al., 1986), adolescent sexual offenders (Borduin et al., 1990), and maltreating parents (Brunk et al., 1987). Such success has been followed by more extensive clinical trials with serious juvenile offenders conducted in Simpsonville, South Carolina, and Columbia, M issouri. M oreover, the successes in Simpsonville and Columbia have led to considerable federal funding to further develop and refine MST, including its extension to other difficult clinical populations (i.e. substance abusing delinquents, and youth presenting with psychiatric emergencies).

\section{Simpsonville, South Carolina (Henggeler et al., 1992)}

In this N IM H-funded study, 84 serious juvenile offenders (i.e. chronic offenders and/or violent offenders) were referred by the Department of Youth Services (DYS) due to their imminent risk for incarceration. Youths were randomly assigned to usual services $(n=41)$ (e.g. court ordered curfew, school attendance, referral to other community agencies) or MST $(n=43)$. Consistent with the judgement of DYS that these youth were at imminent risk of incarceration, $47 \%$ of usual services youth were subsequently incarcerated after referral, and $68 \%$ were incarcerated by the 59 -week follow-up. Participants were involved in extensive criminal activity as evidenced by their average of 3.5 previous arrests and 9.5 
weeks of prior incarceration. In addition, $54 \%$ had at least one previous arrest for a violent offense. The average age of participants was 15.2 years (s.D. $=1 \cdot 4) ; 77 \%$ were male; $56 \%$ were A frican-A merican; $42 \%$ were Caucasian; $2 \%$ were $\mathrm{H}$ ispanic-A merican; $26 \%$ lived with neither biological parent; and the average Hollingshead (1975) social status score was 25 (s.D. $=9$ ) (i.e. semiskilled workers).

Results showed that MST was effective at reducing rates of criminal behavior and out-ofhome-placement. At post-treatment serious offenders in the MST condition reported significantly fewer criminal offenses than their counterparts in the usual services condition. A t the 59-week post-referral follow-up, youth receiving M ST had significantly fewer arrests ( $M=0.87$ vs 1.52$)$ and weeks incarcerated ( $M=5.8$ vs 16.2$)$ than youth receiving usual services. A t post-treatment, youth receiving M ST reported a significantly greater reduction in criminal activity than did youth receiving usual services. Families receiving MST reported more cohesion at post-treatment, while reported family cohesion decreased in the usual services condition. In addition, families receiving M ST reported decreased adolescent aggression with peers, while such aggression remained the same for youth receiving usual services. The survival analysis shown in Figure 1 reveals that at $2 \cdot 4$ years follow-up, M ST approximately doubled the survival rate (i.e. the percentage of youth not rearrested) of these serious juvenile offenders ( $H$ enggeler et al., 1993). M oreover, the relative efficacy of MST was neither moderated by demographic characteristics (i.e. race, age, social class, gender, arrest, incarceration history) nor mediated by psychosocial variables (i.e. family relations, peer relations, social competence, behavior problems, parental symptomatology).

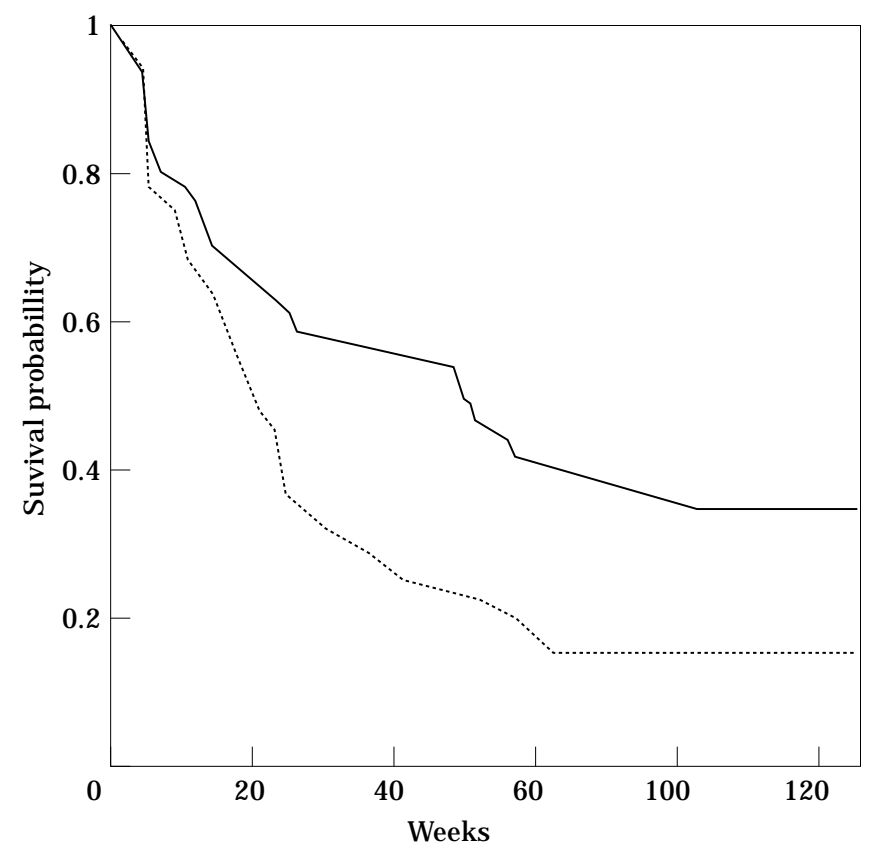

Figure 1. Survival functions for M ultisystemic Therapy (M ST) youth and usual services youth in Simpsonville, SC Project (H enggeler et al., 1993). ( $-=$ M ST ; $\cdots=$ U sual services). 


\section{Columbia, Missouri}

In the most comprehensive and extensive completed evaluation of MST to date, the effectiveness of M ST was compared with individual therapy (IT ). Participants were 20012 to 17-year-old juvenile offenders and their families (Borduin et al., 1995) randomly assigned to receive either MST $(n=92)$ or IT $(n=84)$, with 24 families refusing to participate in either treatment condition. IT focused on personal, family, and academic issues, with therapist providing support, feedback, and encouragement for behavior change. The theoretical orientations of IT therapists $(n=6)$ included psychodynamic (e.g. promoting insight and expression of feelings), client-centered (e.g. building a close relationship, providing empathy and warmth), and behavioral (e.g. providing social approval for school attendance and other positive behaviors) approaches (Borduin et al., 1995).

The juvenile offenders were involved in extensive criminal activity as evidenced by their average of 4.0 previous arrests $(S . D .=1.3)$ and the fact that $61 \%$ had been previously incarcerated. The average age of the youths was 14.7 years (S.D. $=1.6) ; 67 \%$ were male; $67 \%$ Caucasian; $32.2 \%$ A frican-A merican; $65 \%$ were from families characterized by low socio-

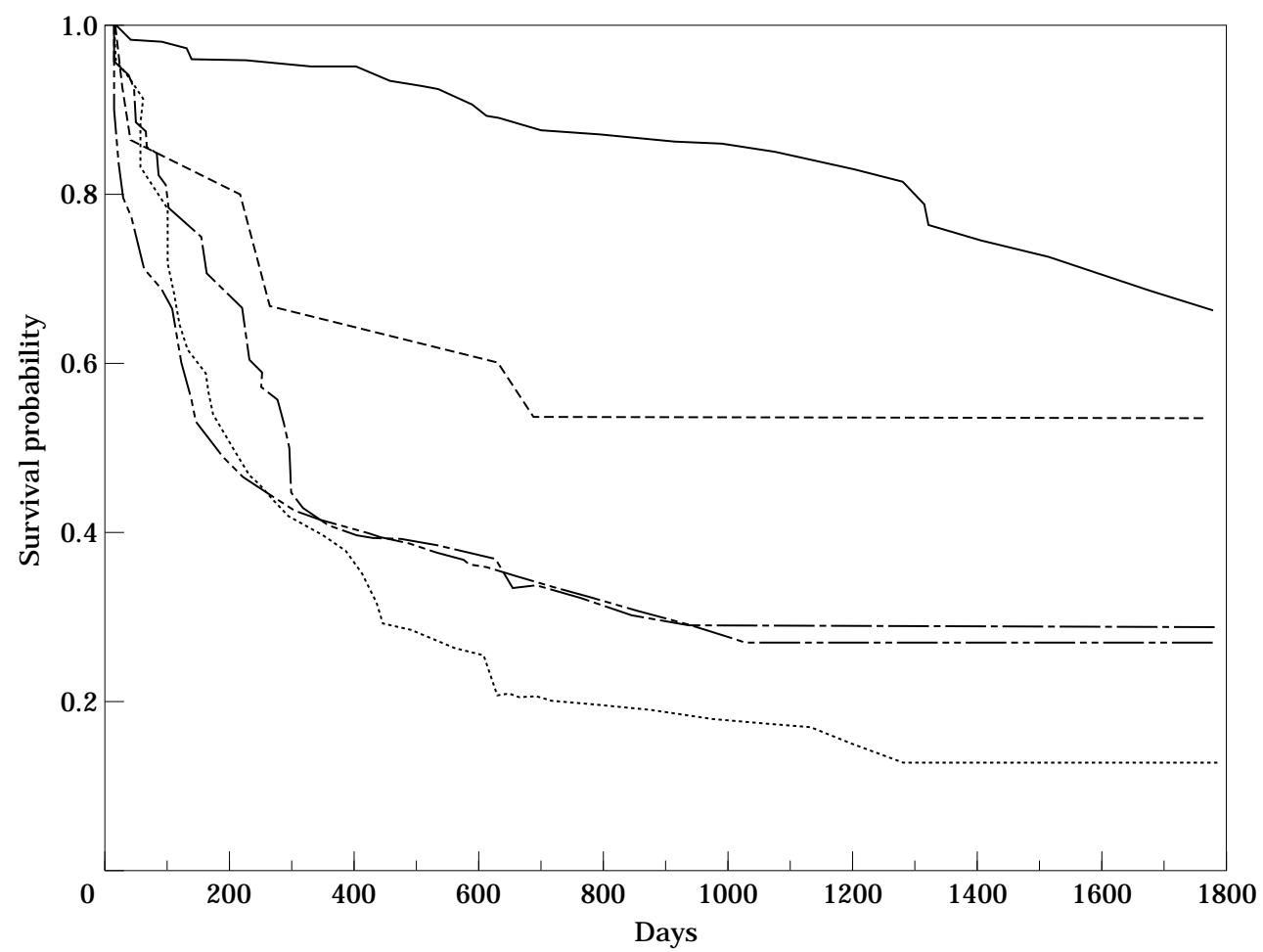

Figure 2. Survival functions for Multisystem Therapy (MST) completers (-), MST dropouts $(----)$, Individual Therapy (IT) completers $(-\cdots-\cdot)$, IT dropouts $(-\cdots-\cdots-)$, and treatment refusers $(\cdots)$ in Columbia, M O Project (Borduin et al., 1995). 
economic class (Hollingshead, 1975); and 50\% lived with two parental figures (e.g. biological parents, step-, foster, or adoptive parents, or other adult relatives.

At post-treatment families receiving MST reported and showed (via observational measures) more positive changes in their dyadic interactions than IT families. For example, MST families reported increased cohesion and adaptability, and showed increased supportiveness and decreased conflict-hostility as compared with IT families. Of note, parents in the M ST group evidenced greater reductions in psychiatric symptomatology than did parents in IT.

Figure 2 reveals that youth receiving MST were also significantly less likely to be rearrested than youth receiving individual therapy at follow-up. Specifically, at approximately 4-year follow-up, MST completers had lower recidivism rates $(n=77,22 \cdot 1 \%$ ) than MST dropouts $(n=15,46 \cdot 6 \%)$, IT completers $(n=63,71 \cdot 4 \%)$, IT dropouts $(n=21$, $71 \cdot 4 \%$ ), and treatment refusers ( $n=24,87 \cdot 5 \%)$. M oreover, M ST dropouts were at lower risk of rearrest than IT completers, IT dropouts, and refusers. Examination of recidivists from each group revealed that M ST youth arrested during follow-up were arrested less often and for less serious offences than IT youth arrested during follow-up. Follow-up data also revealed that M ST youth had a significantly lower rate of substance-related arrests than IT youth ( $4 \%$ vs 16\%) (H enggeler et al., 1991). M ost importantly, M ST youth were less likely to be arrested for violent crimes (e.g. rape, attempted rape, sexual assault, aggravated assault, assault/battery) following treatment than IT youth.

In summary, findings from controlled clinical trials provide strong evidence that MST can produce short-term and long-term reductions in criminal behavior in serious juvenile offenders. M oreover, MST is relatively inexpensive (H enggeler et al., 1992) and is also able to reduce out-of-home placements. Such findings suggest that when contrasted with a clinically-effective family-based treatment, usual services (i.e. incarceration) not only costs more, but also fails to protect the community because returning offenders perpetrate at higher rates than their counterparts treated in the community.

\section{Theoretical and clinical features of multisystemic therapy}

W e believe that the success of M ST is due to several distinctive and innovative features that set it apart from many contemporary treatments and violence prevention approaches.

\section{Theoretical model}

MST is a highly individualized family- and community-based therapeutic approach that is consistent with social-ecological models of behavior (Bronfenbrenner, 1979). Social ecology posits that individuals are nested within a complex of interconnected systems that encompass both proximal (individual, family, peer, school) and distal (neighborhood, community, child and adolescent service systems) social influences. Behavior is seen as the end product of reciprocal interactions between individuals and the interconnected systems in which they are nested. M ST has much in common with family systems (e.g. H aley, 1976; Minuchin, 1974) conceptualizations of behavior, which also emphasize the reciprocal interplay between the child and their familial relations.

MST has several substantive departures from traditional family therapies that are 
pertinent. These acknowledge that (a) antisocial behavior can be maintained by dysfunctional transactions within and/or across various interconnected systems or combinations thereof (which may be outside of the immediate family), (b) behavior is influenced by individual child developmental variables (cognitive abilities, moral reasoning), and (c) the most efficacious intervention for a particular child may be nonsystemic (e.g. using cognitive therapy, behavioral parent training).

\section{Comprehensive services}

The clinical foci of MST closely fit the multidimensional causal models of delinquency and utilizes a comprehensive strategy in case conceptualization and treatment ( $\mathrm{H}$ enggeler and Borduin, in press). A n important aspect of M ST assessment is identifying factors within and between each system or subsystem that may promote or attenuate irresponsible behavior on the part of the youth and family (Henggeler et al., 1994). From this information, a treatment plan is developed in collaboration with the family that integrates interventions within and between family, peers, school, and community systems. A s such, M ST aims to provide the family with total care (e.g. individual, family and marital therapy, peer group interventions, case management) and address barriers to attaining treatment goals (e.g. parental substance abuse/psychopathology, concrete services such as housing).

\section{Family preservation model of service delivery}

MST has been implemented using the family preservation model of service delivery. This model emphasizes providing home-based and family-focused services that are intensive, time limited, pragmatic, and goal-oriented. A s such, services are delivered in "real world settings" (i.e. home, school, neighborhood) with the hope of maintaining youths in their natural environment ( $\mathrm{N}$ el son, 1991). Delivering services via family preservation has several advantages, including: (1) more valid assessment of the contingencies maintaining antisocial behavior and/or the mitigating circumstances that may attenuate treatment gains; (2) enhanced generalization of treatment gains by addressing factors in the youth's social ecology that may have fostered antisocial behavior or may promote positive adaptation; (3) enhanced maintenance of treatment gains by linking adaptive and prosocial behaviors to natural contingencies in the youth's social ecology; (4) communication of respect and partnership in the therapeutic endeavour; and (5) promotion of family co-operation with treatment and minimization of missed appointments.

\section{Treatment specificity}

Treatment specificity is accomplished by therapists adhering to nine intervention principles (see H enggeler et al., 1994), which represent the fundamental nature of M ST. W ithin these guidelines, MST therapists utilize pragmatic and goal-oriented strategies that are based on the empirical literature including techniques derived from behavior therapy (e.g. Blechman, 1985) and cognitive behavior therapy (e.g. Kendall and Braswell, 1985), but does so in a comprehensive and ecological framework. The nine intervention principles are described in the clinical case example that appears at the conclusion of this paper. 


\section{Individualized care}

In light of the unique set of strengths and weaknesses of each family and therapist, M ST therapists develop individualized treatment plans that use specific family strengths to ameliorate identified problems and attain treatment goals. Targeting the unique set of contributing factors operative in each family's social ecology increases the probability of successfully decreasing antisocial behavior.

\section{Empowerment}

A major focus of MST is to empower families by providing them with the skills and resources needed to deal effectively and independently with future difficulties. Toward this end, treatment often focuses on facilitating the development of enduring social support networks within the parents' natural environment (e.g. encouraging rapprochement with extended family, engagement in church/community activities). Time and energy are also devoted to empowering youth to cope with the inevitable challenges they face as they negotiate the many systems in which they are nested. A s such, youth are taught requisite skills (e.g. assertiveness training, anger management) and linked with academic and vocational resources needed for long-term success.

\section{Accountability}

A hallmark of M ST is the emphasis on outcome accountability among therapists, treatment teams and supervisor. Such an emphasis on accountability, based on tangible evidence of behavior change, contrasts with traditional approaches where treatment failures are often attributed to client resistance or lack of motivation. MST therapists are expected to do "whatever it takes" to engage the family and bring about enduring change within the context of the goals and objectives established mutually by the family and therapist (Henggeler et al., 1994). In light of such accountability, therapists must be provided the resources to achieve favorable outcomes (e.g. low casel oads, extensive training, supervisory support, case consultation) and to attenuate the adverse stressors typically encountered in treating serious clinical problems (e.g. therapist burn-out, frustration).

\section{Treatment principles and clinical case example}

MST is a flexible and individualized treatment approach that addresses the multiple determinants of antisocial behavior in the youth's natural ecology. The flexibility and individualization of MST are central to its effectiveness, and, consequently, have been integrated into the treatment manual that largely serves as the basis of our ongoing clinical trials (Henggeler et al., 1994). This manual specifies nine treatment principles that are viewed as central to the multisystemic approach. These principles are noted and described via a clinical case example. 0 ur operating assumption is that M ST is defined by adherence to these principles.

$\mathrm{H}$ omer is a 15-year-old C aucasian male with an extensive history of delinquent behavior 
including assault and battery with intent to kill, simple assault and battery, malicious destruction of real property, trespassing, petty larceny, contempt of court, and resisting arrest. In school, Homer had a reputation for fighting and bullying his peers and had been expelled in the seventh grade for assaulting a classmate and cursing at his teachers. Homer was in a gang of juvenile delinquents who affectionately called themselves "D eath Row". A side from his criminal record and association with deviant peers, $\mathrm{H}$ omer had an extensive history of abusing inhalants, marijuana, and alcohol.

A t the time of referral Homer had recently been released from a 45-day juvenile justice evaluation facility. He resides alone with his mother, who is employed full-time and has a history of alcohol abuse. Homer also has a 17-year-old sister with a history of crack cocaine dependence. She was recently released from a state-supported treatment facility, and at time of referral was living with her boyfriend and his family. A maternal uncle also lived in the community, though he refused to have contact with Homer due to his antisocial behavior. Homer's treatment was provided by a masters-level therapist who adhered to the following M ST treatment principles.

(1) "The primary purpose of assessment is to understand the fit between the identified problems and their broader systemic context." Homer's antisocial behavior and substance abuse "made sense" in light of his ecological context. First, $\mathrm{H}$ omer was deeply committed to a group of deviant peers, who were older, more "street wise", and from families with significant antisocial histories. For example, one of H omer's friends sold drugs for his drugaddicted father (who also sold guns) and was arrested recently for robbing a store at gun point. Second, Homer refused to go to school and spent most school days at home getting high with his peers. $\mathrm{H}$ is mother reported that she often found the house trashed with beer cans strewn about when she returned from work. Third, Homer exhibited attributional biases in the form of attributing hostile intentions to others. For example, he often attributed peer and family members' failure to comply with his requests as "dissing" him (i.e. disrespectful) which was grounds to be aggressive. Fourth, $\mathrm{H}$ omer and his family lived in a neighborhood best described as crime-ridden and drug-infested. Fifth, Homer's antisocial behavior and substance abuse were maintained by his mother's failure to monitor and consequate his behavior. For example, Homer was allowed to stay out as long as he wanted and did pretty much as he pleased.

The mother's parenting style fit her systemic context well. For example, she had a very busy work schedule, lacked adequate parenting skills, and had minimal social support. Low social support was linked with the death of her husband 3 years previously, her mother's recent death, and her estrangement from extended family. A Iso, the mother felt inadequate, hopeless, and fearful in dealing with a large and threatening substance-abusing adolescent without the help of an adult male.

(2) "Therapeutic contacts should emphasize the positive and use systemic strengths as levers for change." Although a number of factors contributed to Homer's antisocial behavior, several stren gths were identified. First, $\mathrm{H}$ omer's mother was emotionally attached to her son and willing to learn new skills (initially she was quite reluctant and fearful). Second, the family had adequate funds for adjunctive and recreational activities. Third, Homer had several individual skills. Until the age of 12 (the age at which he found his father dying of a stroke) $\mathrm{H}$ omer enjoyed sports and excelled in many. A lthough, $\mathrm{H}$ omer had numerous school suspensions and several expulsions, he was intelligent and could become quite personable. Finally, both Homer and his mother wanted him to attend High School rather than continue in the seventh grade ( $\mathrm{H}$ omer only wanted to attend to play football). 
As described subsequently, these strengths were used to facilitate the attainment of treatment goals.

(3) "Interventions should be designed to promote responsible behavior and decrease irresponsible behavior among family members." Both the mother and Homer exhibited irresponsible behaviors that were targeted for change. The mother had a history of "covering up" for Homer when he got into trouble in the community, thus undermining natural consequences. For example, she refused to call the police when she found drugs in the home or when Homer ran away, and she failed to provide meaningful consequences for his misbehavior or to require age-appropriate responsibilities (i.e. he did not have household chores). Homer's irresponsible behavior included failure to comply with his mother's requests, school refusal, association with deviant peers, and substance use and abuse. In addition, H omer often stayed out all night.

The mother's parenting skills and lack of social supports were initially targeted for intervention. A s therapy progressed, the mother was able to see that to "save" H omer (a child she loved very much) required that she consistently monitor his whereabouts, consequate his misbehavior, and allow him to experience natural consequences. This was accomplished by the therapist aligning with the mother, developing mutual goals, and providing the mother with assistance and support. Thus, for example, when he ran away she signed an order with the Probate Court for him to be "picked-up". Similarly, the mother established developmentally appropriate chores for Homer to complete daily and weekly, and provided appropriate rewards and consequences contingent upon completion. $M$ oreover, the mother demanded that $\mathrm{H}$ omer comply with family rules, particularly meeting curfew, completing school assignments, and disassociating with deviant peers. Towards this end, the mother took Homer's door key and refused to allow him in the house after curfew, and actually "put him out of the house" when he continued to associate with drug-using peers (and after less aversive consequences failed). The therapist was readily accessible for the mother (via daily contact in person, by telephone, or pager) as she implemented these new strategies.

(4) "Interventions should be present-focused and action-oriented, targeting specific and well-defined problems." In collaboration with the mother, teachers, coaches, and probation staff, several specific problems were targeted for change. These included: (1) separating from antisocial peers, (2) eliminating drug and alcohol use, (3) following curfew, (4) attending school and completing assignments, and (5) completing household chores. Likewise, the mother with the support of the therapist would: (1) closely monitor Homer's whereabouts, peer associations, and school performance, and (2) provide consequences for inappropriate behavior and rewards for appropriate behavior.

(5) "Interventions should target sequences of behavior within or between multiple systems." A s noted above, several interventions focused on the mother's capacity to interact effectively with her son. Importantly, the mother's social network was enhanced to provide the ongoing support needed to deal effectively with her son. Specifically, with the support of the therapist, the mother became actively involved in church activities and elicited her brother's help and support. In addition, after establishing working relationships with school personnel, the mother communicated weekly concerning her son's school performance and behavior.

(6) "Interventions should be developmentally appropriate and fit the development needs of youth." Homer was 15 years of age and still required considerable family support and encouragement. In light of his age, large physical size, and the fact that he was still in the 
seventh grade, the mother and therapist convinced school personnel to allow Homer to advance into the ninth grade so that he could play football. Homer's athletic prowess, interest in sports, and intelligence increased the probability that this intervention would succeed. It was felt by the therapist and the treatment team that re-entry into school and admittance to the ninth grade would serve to; (1) structure H omer's after-school hours, (2) increase his school bonding, and ( 3 ) increase his association with prosocial peers.

The school, however, needed to be convinced that Homer would improve his academic and behavioral performance if allowed to participate in sports. This was no small accomplishment as the High School principal wrote an assistant superintendent of the school district a letter seeking to block Homer's admittance due to his past failure and assaultive behavior. Clearly, the school needed reassurance that students and staff would be "safe" with $\mathrm{H}$ omer attending. Consequently, the mother and therapist assured the principal and assistant superintendent that in the event Homer had difficulties one or both "would come to the school on a moment's notice", and such difficulties would be firmly addressed.

(7) "Interventions should be designed to require daily or weekly effort by family members." Homer provided his mother with ample opportunities to practice her new parenting skills. A s mentioned above, the mother assigned chores and monitored their completion daily, and if completed, provided rewards. Homer was required to report daily his whereabouts to his mother by leaving notes or calling home. In addition, the mother or the therapist routinely called Homer's teachers to check on behavior and academic progress. Initially, the therapist called the mother daily to offer encouragement and to monitor her progress in completing assignments. In the event the mother did not follow through or failed in her efforts, the therapist reframed failure as "an opportunity to practice", and reinforced successive approximations to the desired behavior.

(8) "Intervention efficacy is evaluated continuously from multiple perspectives." A II aspects of the aforementioned treatment tasks were evaluated from multiple perspectives (i.e. Homer, his mother, school personnel, coaches). The therapist did not rely solely on positive verbal reports from $\mathrm{H}$ omer and his mother, but obtained reports from school personnel as well as probation staff. In addition, the therapist observed periodically H omer's classroom behavior and interactions during football practice.

(9) "Interventions should be designed to promote treatment generalization and longterm maintenance of therapeutic change." The mother's decision to provide $\mathrm{H}$ omer with natural consequences, monitor his whereabout and school behavior, enroll him in the ninth grade and high school football, provide age-appropriate expectations, and enhance her own social support network (i.e. rapprochement with extended family members and school personnel) provided an ecological context in which Homer was on a path of positive psychosocial development. $\mathrm{He}$ is now enrolled in $\mathrm{H}$ igh School and has been making $\mathrm{A}$ and $B$ grades. He has become one of the star junior varsity football players and plans to play basketball and baseball during the upcoming year. These sports activities have provided Homer with a predominantly prosocial peer group and have given him substantial opportunities to obtain social approval from his mother and school personnel. Consequently, he has not expressed interest in seeing his former gang members nor does he "feel the urge to hurt someone when I feel bad". He has gained a new sense of self-worth from the positive feedback he gets from his mother and fellow students.

Concomitantly, as the mother has been successful in "gaining control of my house", she too has evinced a greater sense of empowerment. $\mathrm{Her}$ affect is much brighter and she has developed a closer relationship with her well-adjusted brother who has begun to spend time 
with $\mathrm{H}$ omer. In addition, $\mathrm{H}$ omer's home and school environments are now more nurturing and less adversarial, and hence his aggressive and violent acting-out has been eliminated. A Iso, when problems arise in school or at home they can be addressed quickly as the mother has established personal relations with Homer's teachers and principal (who has now taken a special interest in him).

In summary, MST interventions have given $\mathrm{Homer}$ an opportunity to become a responsible citizen whereas his previous behavior and academic failure were almost assuring him a life of crime, violence, addiction, and minimal subsistence. Successful outcome was accomplished by applying a multifaceted approach to assessment and treatment, addressing the unique factors surrounding Homer's antisocial behavior, empowering Homer and his mother, and providing treatment directly in their social ecology.

\section{Conclusion}

A s evidenced by our clinical trials and exemplified in H omer's case, M ST offers at least two opportunities to prevent violence. First, youths who engage in serious antisocial behavior also engage in behaviors that place them at high-risk for criminal victimization (e.g. carrying weapons) (M ercy et al., 1993). Consequently, criminal victimization may be reduced by changing high-risk behavior patterns such as carrying weapons, staying out all night, and associating with gang members. Second, the perpetration of violence can be reduced by successfully targeting high-risk youth whose families are responsible for the vast majority of crimes in many communities (W olfgang et al., 1972; W est and Farrington, 1973; H uesmann et al., 1984). A s M oore (1993) noted: ". . . if we could limit those who commit violence to only one crime in their career, a great deal of violence would be prevented, for much violence comes from offenders who are persistent and active" (p. 37). In light of the broad range of psychosocial difficulties exhibited by serious juvenile offenders and their cost to society, violence prevention strategies that are relatively complex, recognize the multiple determinants of such behavior, and target youth at greatest risk of commiting such acts may help to "stem the tide".

\section{References}

A gnew, R. (1985). Social control theory and delinquency: a longitudinal test. C riminology, 23, 47-61.

A lbee, G. W. (1989). Primary prevention in public health: Problems and challenges of behavior change as prevention. In Primary Prevention of A ID s: Psychological A pproaches, M ays, V . M ., et al. (Eds). N ewbury Park: Sage.

Blechman, E. A . (1985). Solving C hild B ehavior Problems at H ome and School. C hampaign, IL: Research Press.

Borduin, C. M., Henggeler, S. W., Blaske, D. M. and Stein, R. (1990). Multisystemic treatment of adolescent sexual offenders. International Journal of $O$ ffender Therapy and Comparative C riminology, 34, 105-113.

Borduin, C. M., M ann, B. J., Cone, L. T., H enggeler, S. W ., Fucci, B. R., Blaske, D. M. and W illiams, R. A . (1995). M ultisystemic treatment of serious juvenile offenders: long-term prevention of criminality and violence. Journal of $C$ onsulting and C linical Psychology, 63, 569-578.

Bronfenbrenner, U. (1979). The Ecology of Human Development: Experiments by nature and design. Cambridge, $\mathrm{MA}$; $\mathrm{H}$ arvard U niversity Press. 
Brunk, M., Henggeler, S. W. and W helan, J. P. (1987). Comparison of multisystemic therapy and parent training in the brief treatment of child abuse and neglect. Journal of Consulting and Clinical Psychology, 55, 171-178.

Coie, J. D., W att, N. F., W est, S. G., H awkins, J. D., A sarnow, J. R., M arkman, H. J., Ramey, S. L., Shure, M. B. and Long, B. (1993). The science of prevention: a conceptual framework and some directions for a national research program. A merican Psychologist, 48, 1013-1022.

Elliott, D. S., Huizinga, D. and A geton, S. S. (1985). Explaining D elinquency and Drug U se. Beverly $\mathrm{H}$ ills, CA : Sage.

Fagan, J. and W exler, S. (1987). Family origins of violent delinquents. C riminology, 25, 643-669.

Federal Bureau of Investigation. (1992). U niform C rime Reports for the U .S. 1991 W ashington: D.C.: U.S. G overnment Printing 0 ffice.

Haley, J. (1976). Problem Solving T herapy. San Francisco: Jossey-Bass.

Henggeler, S. W. (1991). Multidimensional causal models of delinguent behavior and thie implications for treatment. In R. Cohen and A. W. Siegel (Eds.). Context and Development. $\mathrm{H}$ illsdale, N J: Lawrence Erlbaum.

Henggeler, S. W . and Borduin, C. M . (1990). Family Therapy and Beyond: A multisystemic approach to treating the behavior problems of children and adolescents. Pacific G rove, CA : Brooks/C ole.

Henggeler, S. W . and Borduin, C. M. (in press). M ultisystemic treatment of juvenile offenders and their families. Forthcoming chapter in Family and H ome Based Services, Schwartz, I. M. (Ed.). Lincoln, N E: U niversity of N ebraska Press.

Henggeler, S. W., Borduin, C. M., M elton, G. B., Mann, B. J., Smith, L., H all, J. A., Cone, L. and Fucci, B. R. (1991). Effects of multisystemic therapy on drug use and abuse in serious juvenile offenders: a progress report from two outcome studies. Family Dynamics A ddiction Q uarterly, 1, 40-51.

Henggeler, S. W ., M elton, G. B. and Smith, L. A . (1992). Family preservation using multisystemic therapy: an effective alternative to incarcerating serious juvenile offenders. Journal of $C$ onsulting and Clinical Psychology, 60, 953-961.

Henggeler, S. W., M elton, G. B., Smith, L. A., Schoenwald, S. K. and Hanley, J. H. (1993). Family preservation using multisystemic treatment: long-term follow-up to a clinical trial with serious juvenile offenders. Journal of C hild \& Family Studies, 2, 283-293.

Henggeler, S. W., Rodick, J. D., Borduin, C. M., Hanson, C. L., W atson, S. M. and U rey, J. R. (1986). M ultisystemic treatment of juvenile offenders: effects on adolescent behavior and family interaction. D evelopmental Psychology, 22, 132-141.

Henggeler, S. W. and Schoenwald, S. K. (1994). Boot camps for juvenile offenders: just say no. Journal of $C$ hild and Family Studies, 3, 243-248.

H enggeler, S. W., Schoenwald, S. K., Pickel, S. G., Brandino, M. J., Borduin, C. M. and H all, J. A . (1994). T reatment M anual for Family Preservation U sing M ultisystemic Therapy. C harleston, SC: South $\mathrm{C}$ arolina $\mathrm{H}$ ealth and $\mathrm{H}$ uman Services Finance Commission.

Hollingshead, A. B. (1975). Four Factor Index of Social Status. Unpublished manuscript, Yale U niversity, Department of Sociology, $\mathrm{N}$ ew Haven.

H uesmann, L. R., Lefkowitz, M. M., Eron, L. D. and W alder, L. O. (1984). Stability of aggression over time and generations. D evelopmental Psychology, 20, 1120-1134.

H uizinga, D., Esbensen, F. A ., van Kammen, W. B. and Thornberry, T. P. (1993). Epidemiology. In D. H uizinga, R. Loeber, and T. P. Thornberry (Eds). U rban D elinguency: T echnical Report. O ffice of Juvenile Justice and Delinguency Prevention, U .S. Department of J ustice, W ashington, D. C.

Kazdin, A. E. (1987). Treatment of antisocial behavior in children: current status and future directions. Psychological Bulletin, 102, 187-203.

Kendall, P. C. and Braswell, L. (1985). Cognitive-behavioral Therapy for Impulsive C hildren. N ew York: Guilford.

Kendall, P. C . and Braswell, L. (1993). C ognitive-behavioral Therapy for I mpulsive C hildren, (2nd Edn). $\mathrm{N}$ ew York: Guilford.

Leitenberg, H. (1987). Primary prevention of delinquency. In Prevention of Delinquent Behavior: Vol. X. Primary prevention of psychopathology, Burchard, J. D. and Burchard, S. N. (Eds). N ew York: Sage.

Lipsey, M . W . (1992). The effects of treatment on juvenile delinquents: Results from meta-analysis. Paper presented at the N IM H M eeting for Research to Prevent Youth Violence, Bethesda, M D. 
M ercy, J. A ., Rosen berg, M. L., Powell, K. E., Broome, C. V. and Roper, W . L. (1993). Public health policy for preventing violence. $\mathrm{H}$ ealth $\mathrm{A}$ ffairs, 12, 7-29.

M inuchin, S. (1974). Families and F amily T herapy. C ambridge, M A : H arvard U niversity Press.

Moore, M. H. (1993). Violence prevention: criminal justice or public health? H ealth A ffairs, 12, 34- 45.

$\mathrm{N}$ elson, K. E. (1991). Populations and outcomes in five family preservation programs. In Family Preservation Services: Research and evaluation. K. W ells and D. E. Biegel (Eds). N ewbury Park, CA : Sage.

Office of Juvenile Justice and Delinquency Prevention. (1993). U rban Delinquency and Substance A buse: T echnical Report. Office of Justice Programs. W ashington, DC: U.S. Department of Justice.

Patterson, G. R. and Dishion, T. J. (1985). Contributions of families and peers to delinquency. C riminology, 23, 63-79.

Rappaport, J. (1981). In praise of paradox: a social policy of empowerment over prevention. A merican J ournal of C ommunity Psychology, 9, 1-25.

Simcha-Fagan, O. and Schwartz, J. E. (1986). N eighborhood and delinquency: an assessment of contextual effects. C riminology, 24, 667-703.

W est, D. J. and Farrington, D. P. (1973). W ho Becomes D elinquent? London: Heinemann.

W inett, R. A ., Riley, A. W ., King, A . C. and A Itman, D. G. (1989). Prevention in mental health: A proactive-development-ecological perspective. In $\mathrm{H}$ andbook of $\mathrm{C}$ hild Psychopathology, Ollendick, T. H. and Hersen, H. (Eds). N ew York: Plenum.

Wolfgang, M. E., Figlio, R. M. and Sellin, T. (1972). Delinquency in a Birth Cohort. Chicago: U niversity of C hicago Press. 